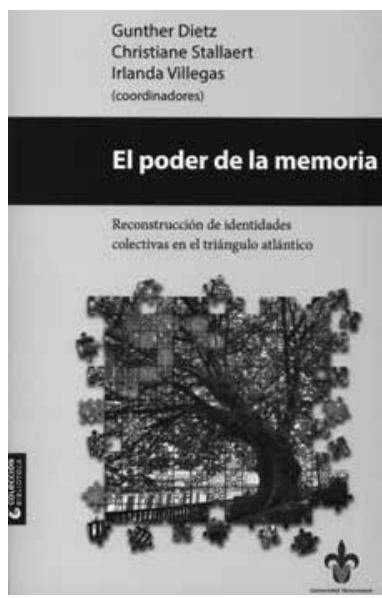

New Contributions to the

Transatlantic Research on Social Memory

Miguel Figueroa SAAVEdra

Instituto de Investigaciones en Educación, Universidad Veracruzana, Xalapa, Veracruz, México migfigueroa@uv.mx

Desacatos 58 , septiembre-diciembre 2018, pp. 209-213
El poder de la memoria.

Reconstrucción de identidades

colectivas en el triángulo atlántico

Gunther Dietz, Christiane Stallaert

E IRLANDA VILLEGAS (COORDS.), 2016

Universidad Veracruzana, Xalapa

\section{Nuevas aportaciones al estudio transatlántico de la memoria social}

\author{
MIGUEL FIGUEROA SAAVEDRA
}

a publicación póstuma del libro de Maurice Halbwachs, La mémoire collective, en 1950, dio pie a considerar la memoria un objeto de estudio sociológico. Hasta entonces, la memoria se había tomado como un concepto esencial, vinculado de manera indisociable a la historiografía. En adelante, se fue mostrando como un fenómeno construido socialmente que, por lo tanto, podía ser estudiado desde varias perspectivas y disciplinas. De esta manera, se ha convertido en un concepto epistemológico que permite ahondar en el aspecto diacrónico de la construcción de la identidad, pero también en el carácter cambiante de los contextos que exigen esas construcciones.

A partir de este giro, el estudio antropológico y sociológico de la memoria empezó a definirse en la década de 1990 (Connerton, 1989), cuando sucesos como la caída del bloque soviético, el incremento de los flujos migratorios a la Unión Europea y Estados Unidos, la hipertecnologización del acceso y manejo de la información y la comunicación, y la generación de culturas híbridas y transnacionales supuso redibujar las identidades asentadas en la memoria histórica. 
Términos como "memoria colectiva", "memoria social" o "memoria cultural" empezaron a abrirse camino de modo fructífero, como un aspecto que se transfiere a algo más que el registro documental de los hechos y las genealogías: las ceremonias, el cuerpo, los medios de comunicación, los relatos, las geografias, las migraciones, las iconografías, los nombres, la lengua, todo forma parte de un complejo artificio cultural que establece el valor social del recuerdo y el olvido en la construcción de la identidad personal y colectiva.

Tanto la afirmación de la identidad como de la tradición requerían una articulación de la memoria social maleable, que permitiera a las comunidades humanas fijar aspectos que fueran significativos para explicar su condición presente y futura, y dotarse de elementos performativos, discursivos e ideativos que los vincularan y expresaran en sus nuevos contextos. Como un fenómeno de cognición social, ese proceso implica, además, la innovación y la mistificación, actos que no están exentos de generar conflictos y contradicciones, aunque también de resolverse como parte de procesos dialógicos dentro y entre grupos humanos.

Sin embargo, la definición y tratamiento de la memoria como construcción social se estudió desde conceptos difusos y en ausencia de un desarrollo teórico compartido entre las ciencias sociales, como menciona Ana Ramos (2011: 132) cuando cita las reflexiones que a finales de esa década se planteaban en el terreno de la sociología y la historia sobre la memoria colectiva (Olick y Robbins, 1998: 106).

En el siglo XXI, sigue siendo un tema apasionante, reavivado por la dimensión política de la memoria, que la hace, no ya un fenómeno derivado de la "inmersión" dentro de un determinado grupo social o cultural, sino un elemento cultural que sirve a las necesidades de "explicarse" y "entenderse", pero también de "reconstruirse", y permite redibujar, revisar, incluso manipular nuestra identidad personal y social, y justificar una dicotomía naturalizada entre tradición y modernidad.

En ese camino, encontramos trabajos como Los abusos de la memoria, de Tzvetan Todorov (2013), en el que reflexiona sobre la instrumentalidad del recuerdo y su puesta al servicio de la construcción de una memoria al servicio del poder. En estos contextos de "revisión" de la memoria histórica — esa polaridad de la memoria que supone querer recordar y querer olvidar-, la construcción social de la memoria, más que perseguir la conservación de un recuerdo, lo que busca es resistirse a olvidarlo. A este respecto, y como mostraba en su revisión del estado del arte, Ana Ramos concluía que:

Sin cerrar ninguno de los debates presentados [...], estas lecturas nos permiten empezar a incorporar los reclamos que algunos grupos y personas realizan en nombre de la memoria de sus ancestros. Reclamos de marcos de interpretación alternativos y de sus propias tradiciones epistemológicas de conocimiento, reclamos de verdad que desafían las imágenes dominantes sobre el pasado y reclamos de autonomía en las decisiones que involucran el curso de su historia (2011: 144).

En esta compleja e imbricada relación entre poder, resistencia e historia colectiva y personal, estos debates contemplan la memoria y la historia como fundamentos que establecen un principio de certeza en la comprensión de los procesos sociales. Se muestra de este modo cómo la memoria se pone al servicio de la definición contingente de un ser social.

En este marco se integra la aportación del libro El poder de la memoria. Reconstrucción de identidades colectivas en el triángulo atlántico. Los estudios de caso que contiene plantean continuar profundizando en los fenómenos de la memoria, pero también de desmemoria, que se desarrollan hoy en el marco de la globalización y la transnacionalización. Como señalan los antropólogos Gunther Dietz y Christiane 
Stallaert, la memoria es una recuperación, una reconstrucción de lo "propio" en procesos en los que la dimensión temporal y espacial se ven sacudidos por la transterritorialidad y la interculturalidad de las ubicaciones y relaciones de los sujetos que tratan de mantener una identidad distintiva frente a lo ajeno. El contexto, el espacio que da unidad a estos estudios, es precisamente el mundo atlántico como región de interconexión en la que por migración, exilio, diáspora o secuestro masivo se ha configurado históricamente un "paisaje de memoria", en el que la conservación o la recuperación de la memoria se ha transformado en un ejercicio de poder en las políticas de la identidad.

Por lo tanto, como se acota en este libro, el poder de la memoria se transforma también en una memoria del poder, no sólo en el sentido estructural y orgánico de la sociedad o de la expansión colonizadora e imperialista de las naciones, sino en la capacidad de acción de los grupos humanos para su transformación o conservación ante los diferentes contextos y situaciones vivenciales de la colectividad y las culturas.

Desde su título, el libro quiere poner en situación al lector — especialista o interesado- sobre la posibilidad de ahondar en los fenómenos de etnogénesis y políticas de identidad en el amplio espacio de las dos orillas del océano Atlántico, en torno a grupos y colectivos cuya memoria y recuperación, pero también su desmemoria y olvido, se ha desplazado a través de esa territorialidad líquida que enlaza América, Europa y África.

La estructura del libro es por lo menos conmovedora, y cuanto más, motivadora, al invitarnos a revivir esos tránsitos entre sendas orillas y entender lo que para muchos pueblos ha representado el reto de "rememorar" su origen y presencia. Como se ha dicho, las experiencias y situaciones son variadas, y a su organización responde el hecho de que el libro se divida en tres conjuntos de contribuciones: 1) memorias desterradas, memorias itinerantes;
2) memorias amputadas, memorias reterritorializadas, y 3 ) memorias devoradas, memorias regeneradas.

El primer conjunto se compone de tres estudios sobre aspectos poco considerados por nuestra mirada cultural, como los sueños, los nombres y las devociones imagineras, que muestran la dimensión etnográfica de la memoria como parte de los relatos de vida y la conformación del tejido social. El capítulo "La memoria de los que estaban y de los que no estaban: sueños y visiones en la España contemporánea" (pp. 17-39), de la antropóloga Arianna Cecconi, analiza de modo comparativo el papel que juega la memoria onírica en el contexto de los conflictos sociales. Así, aquellos que vivieron la guerra civil en Perú y España muestran cómo su historia personal y familiar se hace presente en sus sueños, no como un viaje al pasado, sino como una visita del pasado en el presente, en un tiempo sin historia, cuya interpretación y validación como "recuerdo" se ve muy condicionada por el valor cultural que se otorga a lo onírico y la actualidad social de la memoria histórica como tema político. En "El nombre, lugar de memoria de la identidad prohibida" (pp. 41-57), Christiane Stallaert, también de modo comparativo, revisa procesos históricos en los cuales el cambio del nombre se ha manifestado como una transformación planeada de la identidad. Examina el papel que juega el nombre personal en la estrategia de conservación o negación de la memoria en el exilio y retorno de las comunidades judías, primero en la península ibérica durante los procesos de persecución, conversión forzada y expulsión entre los siglos XIV y XV, también en el caso morisco en el siglo XVI, y luego el proceso de extranjerización, deportación y exterminio durante el régimen nacionalsocialista en Alemania en el siglo XX. En esos casos, el nombre como etiqueta es como un depósito de memoria que conviene afirmar o negar en contextos de rechazo y resistencia. Cierra este bloque el capítulo "Memoria colectiva, religión e identidad: el Señor de los Milagros, de huaca andina a patrono 
espiritual de los migrantes peruanos en Bélgica" (pp. 59-85), de Carmen Núñez-Borja, que analiza cómo la devoción a la imagen del Cristo de los Milagros trasciende el acto religioso para mostrarse como un elemento en el que se articula una memoria colectiva y cultural que reafirma la identidad peruana en contextos de migración internacional, hasta el punto de constituirse en una comunidad de memoria y con ello en un medio de protesta y resistencia pública hacia la sociedad receptora.

El segundo bloque estudia no tanto procesos paralelos o migraciones más o menos forzadas, sino el papel de la memoria en procesos de desarraigo y rapto masivo, como fue el tráfico de esclavos de África a América. El capítulo “The Middle Passage (la trata atlántica)" (pp. 89-127), de Irlanda Villegas, se refiere a las controversias que aún subsisten en torno a la memoria histórica sobre este episodio en Estados Unidos. Mediante el análisis de la obra literaria de la escritora afroamericana Toni Morrison, se hace evidente el uso de la novela histórica, no meramente como un registro de recuerdos con la finalidad de dar testimonio, sino por la capacidad de la literatura para revivir emocionalmente la historia y hacer que el lector incorpore por medio del lenguaje esos recuerdos como parte de su memoria. En este caso, la literatura se manifiesta como un vehículo tanto de recuperación y transmisión de una identidad colectiva como de responsabilidad y reconciliación social.

El capítulo de la antropóloga Argelia Ramírez Ramírez, "Fragmentos de la memoria histórica en una comunidad de origen afromestizo" (pp. 129145), habla de la memoria histórica como memoria selectiva. De esta manera, y a diferencia del estudio anterior, en su investigación de campo en una comunidad de afrodescendientes en Veracruz, México, el recurso de la "amnesia" como silencio, olvido o ignorancia sobre su pasado esclavista responde a una estrategia de resignificación en la que otros episodios históricos cobran mayor relevancia para entenderse e identificarse como comunidad. De igual modo, el trabajo de la antropóloga Gloria Lara Millán, "Afromexicanos y negros: memoria y movilización política" (pp. 147-165), considera la estrecha relación entre movimientos sociales y memoria histórica en el caso de la población afromexicana y la dificultad para hacer de este referente un elemento importante para la construcción de una identidad étnica. En este caso, la "memoria de la piel" permite ahondar en la dimensión política de la memoria de la negritud en la reivindicación de derechos y el reconocimiento de la identidad por parte de organizaciones afro en Oaxaca y Guerrero.

El estudio presentado por Christiane Stallaert y Kaat Torfs, "La fuerza de la memoria colectiva en la lucha por un territorio. Los afroesmeraldeños en busca de justicia" (pp. 167-178), ubica un problema semejante al del caso mexicano en el contexto ecuatoriano. Ante la identidad mestiza, las poblaciones afrodescendientes reivindican una memoria colectiva cuyos fundamentos son la etnoeducación y la ancestralidad.

En el último conjunto de estudios se reflexiona sobre los fenómenos en los que la memoria persiste con nuevas reelaboraciones. La antropóloga Maya Lorena Pérez Ruiz, en su texto "Memoria, identidades y relaciones interétnicas en el área maya de Yucatán, México" (pp. 181-221), describe una sociedad yucateca en la que la identidad maya y la organización social en la que se inscribe aún se articula de manera similar a como se organizaba la sociedad virreinal, pero de un modo más asimétrico y jerárquico si cabe, en el que existe una separación entre indiosmaceguales, mayeros y vecinos "españoles", con una memoria que atraviesa todos los episodios históricos - Guerra de Castas, Revolución mexicana - protagonizados por una comunidad ubicada en un territorio marginal del proyecto nacional mexicano.

La antropóloga Yara Altez presenta "El olvido y la des-memoria en comunidades afrodescendientes de la costa central venezolana" (pp. 223-242). A diferencia del bloque anterior, se muestra el caso de las comunidades de afrodescendientes que 
han desarrollado un filtro de recuerdos en el que el olvido o la negación de su esclavitud originaria se emplean como una estrategia para sentirse representados en una modernidad más integrada.

Por último, con el estudio "Los usos de la tradición en un pueblo acateko de Chiapas, México" (pp. 243-258), la antropóloga Verónica Ruiz Lagier comenta el caso de una comunidad indígena, los akatekos, que desde la década de 1980 llegó a México desde Guatemala en busca de refugio a causa de la guerra civil. En esas circunstancias, la memoria colectiva se asienta en la pervivencia de sus fiestas patronales y la coronación de la reina indígena, al mismo tiempo que articula una etnogénesis que mexicaniza su identidad indígena y recrea su tradición en una nueva estructura histórica.

La estructura que organiza los estudios de caso en amplios marcos, que no dejan de estar conectados y relacionados, permite fijar aspectos característicos de la construcción de la memoria en un mundo globalizado, en el que la lejanía y la cercanía no se comprende sólo desde una dimensión espacial, sino desde una dimensión temporal, mediática y virtual. En este marco, los mundos psíquicos, familiares, corporales y sociales son más difíciles de controlar; lo olvidado y negado aflora como incómodo recuerdo, o lo mantenido y recordado se muestra como recreación que positiva su representación social. En todos los casos se logra explorar la complejidad de eso que llamamos memoria y que constituye el elemento más definidor de lo que entendemos como identidad cultural.
Hay que señalar que algunos de los trabajos incluidos son investigaciones más extensas que exponen resultados preliminares o tangenciales de otros temas centrales. Esto puede hacer que algunas de sus conclusiones todavía sean objeto de discusión o no hayan logrado llevarse más allá en las implicaciones que contienen para esclarecer ciertos debates sobre la función social de la memoria. Más que un demérito, éste es un gran estímulo para el lector, pues le permite participar en la enunciación de nuevas vías de indagación a partir de investigaciones recientes que trabajan con estos temas en América y Europa, y también nos invita a apreciar las posibilidades de investigación etnográfica que ofrece esta perspectiva para una variedad situaciones sociales e históricas. En todo caso, se consigue reconocer la importancia de incluir la memoria como un elemento de análisis sociológico y antropológico, no sólo para comunidades que han sufrido procesos de desarraigo, traslado o reacomodo, sino para los retos que supone hoy la rememoración para la construcción de identidades transnacionales y supranacionales y el mantenimiento de las identidades locales y nacionales.

La lectura de estos trabajos permite situarnos como participantes y creadores de esas memorias, y nos ayuda a reconocer procesos, estrategias y elementos que nos constituyen cada día como sujetos históricos y dar un sentido colectivo a cómo nos recordamos en el devenir de nuestras vidas, cómo nos reconocemos en el olvido y el recuerdo de nuestro ser social. D

\section{Bibliografía}

Connerton, Paul, 1989, How Societies Remember, Cambridge University Press, Cambridge.

Halbwachs, Maurice, 1950, La mémoire collective, Presses universitaires de France, París.

Olick, Jeffrey y Joyce Robbins, 1998, "Social Memory Studies: From 'Collective Memory' to the Historical Sociology of Mnemonic Practices", en Annual Review of Sociology, vol. 24, pp. 105-140.

Ramos, Ana, 2011, “Perspectivas antropológicas sobre la memoria en contextos de diversidad y desigualdad”, en Alteridades, vol. 21, núm. 42, pp. 131-148.

Todorov, Tzvetan, 2013, Los abusos de la memoria, Paidós, Barcelona. 